\title{
A methodology for multivariate phenotype-based genome-wide association studies to mine pleiotropic genes
}

\author{
Sung Hee Park, Ji Young Lee, Sangsoo Kim ${ }^{*}$ \\ From 22nd International Conference on Genome Informatics \\ Busan, Korea. 5-7 December 2011
}

\begin{abstract}
Background: Current Genome-Wide Association Studies (GWAS) are performed in a single trait framework without considering genetic correlations between important disease traits. Hence, the GWAS have limitations in discovering genetic risk factors affecting pleiotropic effects.

Results: This work reports a novel data mining approach to discover patterns of multiple phenotypic associations over 52 anthropometric and biochemical traits in KARE and a new analytical scheme for GWAS of multivariate phenotypes defined by the discovered patterns. This methodology applied to the GWAS for multivariate phenotype highLDLhighTG derived from the predicted patterns of the phenotypic associations. The patterns of the phenotypic associations were informative to draw relations between plasma lipid levels with bone mineral density and a cluster of common traits (Obesity, hypertension, insulin resistance) related to Metabolic Syndrome (MS). A total of 15 SNPs in six genes (PAK7, C20orf103, NRIP1, BCL2, TRPM3, and NAV1) were identified for significant associations with highLDLhighTG. Noteworthy findings were that the significant associations included a mis-sense mutation (PAK7:R335P), a frame shift mutation (C20orf103) and SNPs in splicing sites (TRPM3).

Conclusions: The six genes corresponded to rat and mouse quantitative trait loci (QTLs) that had shown associations with the common traits such as the well characterized MS and even tumor susceptibility. Our findings suggest that the six genes may play important roles in the pleiotropic effects on lipid metabolism and the MS, which increase the risk of Type 2 Diabetes and cardiovascular disease. The use of the multivariate phenotypes can be advantageous in identifying genetic risk factors, accounting for the pleiotropic effects when the multivariate phenotypes have a common etiological pathway.
\end{abstract}

\section{Background}

Genome-wide association studies (GWAS) have broadened our knowledge on architectures of disease susceptible loci for many common disease of public health importance. A general approach for GWAS follows a strategy to investigate the correlations between single genetic variants and single traits within a univariate framework. The GWAS have not considered complicated genetic nature such as pleiotropy that occurs due to potential genetic correlation between different traits

\footnotetext{
* Correspondence: sskimb@ssu.ac.kr

Department of Bioinformatics and Life Science, Soongsil University, Seoul, R. O. KOREA
}

$[1,2]$. Thus, it tends to be restricted to identify pleiotropic genes that situated at common etiologic pathways of correlated human diseases.

Patterns of pleiotropic effects have been observed more with an increasing number of variants identified through GWAS [3]. For instances, Winkler and colleagues identified a variant of TCF2 (Transcription Factor 2) associated with T2D [4], while a different variant in the same gene was associated with an increased risk of prostate cancer [5]. These two studies indicate that the risk allele for prostate cancer protects from T2D with an odds ratio of 0.91 . In addition, two studies [3] showed that the same variant in GDF5 associated with 
greater height also was associated with reduced risk of osteoarthritis [6,7].

As we have mentioned the examples above, previous work has shown that ignoring pleiotropic effects may cause imprecise phenotype definition of heterogeneous samples or even spurious associations. A bias in sampling cases and controls characterizing single traits might be propagated since the sampling errors tend to be correlated if the single traits were correlated. This may confound the interpretation of results. Although any loss of power occurred by selection of samples can be recovered by increasing the sample size, the sample size of the GWAS has cost constraints. With large sample sizes of several thousand cases and controls there has been usually limited study power to detect alleles of modest effect sizes (e.g., an odds ratio of 1.20) [8].

In this regard, incorporation of the multiple phenotypes to the GWAS can be an alternative way to unravel missing heritability in the GWAS and to find pleiotropic genes. Even though the GWAS of multivariate phenotypes are known to enhance the power of the GWAS such an approach has not been well established.

To perform multiple phenotypes based GWAS, application of traditional GWAS approaches has suffered penalties from multiple testing problems caused by testing multiple genome-wide scans of single traits separately. This may diminish the power of GWAS due to elevating heterogeneity and bias in samples. Statistically classic multivariate methods have been applied to GWAS of multivariate phenotypes to tackle in an effective manner. Such methods are likelihood-based mixed effects model (LME) $[9,10]$ and generalized estimating equations (GEE) methods. Liu et al. suggested an extension of the GEE to test association analysis for a mixture of continuous and binary traits [11]. Their work manifested statistical power of bivariate association analysis with two continuous traits, i.e. obesity and osteoporosis. Their method is limited to bivariate traits and applicable to independent samples.

O'Brien model [12] and its extension [13], which suggested the integration of results from association tests of single traits of a multivariate phenotype, can work well for a homogeneous mean among individual tests of single traits but not for heterogeneous ones. To overcome this limitation, Yang et al. [2] improved O'Brien method by use of a sample splitting method and a cross validation method as a screening tool for detecting pleiotropic effects. Previous work has contributed to addressing association tests for multivariate phenotypes. However, there is still no standard method to be free from multiple test problems and be accepted for multivariate phenotypes [11].

Much work have not investigated what types of single traits can be correlated to induce multivariate phenotypes. In this context, we aimed to discover novel multivariate phenotypes from large scale epidemiological data by a data mining approach and develop a scheme to GWAS of multivariate phenotypes. In our previous work [14], we reported the discovery of multivariate phenotypes by applying association rule mining over 52 anthropometric and biochemical traits in Korea Association Resource (KARE)[15] population. We showed an analytical scheme for GWAS of the multivariate phenotype lowLDLhighTG, which means a negative relation between low levels of LDL and high levels of TG. Our preliminary results revealed that effect sizes (odds ratios $=1.44-2.38$ ) of genetic loci associated with the multivariate phenotype were higher than genetic loci identified in the initial GWAS, while their p-values were less significant than those in the initial GWAS. Those loci cannot be detected within a single trait based framework.

Here, we present a more sophisticated scheme for refining association rules to extract patterns of phenotypic associations and to visualize them graphically. As a case study, we describe the results of GWAS for multivariate phenotype highLDLhighTG combining elevated low density lipoprotein cholesterol (LDL-C) levels and elevated triglyceride (TG) levels, which have an important clinical implication in metabolic syndrome (MS).

An association rule which expresses patterns of multivariate phenotypes encoding partial correlations between single traits specifies quantitative descriptions of the single traits. Association rules can provide explicit boundaries of the single traits of multivariate phenotypes for optimal selection of both cases and controls. This work contributes a methodology for exploration in GWAS analysis of multiple phenotype highLDLhighTG.

\section{Methods}

\section{Data}

We investigated $350 \mathrm{~K}$ variants in 8,512 individuals in Korea Association Resource (KARE) for performing GWAS of multivariate phenotypes and mining patterns of them. Additional details of quality-control and imputation procedures have been reported in [15]. Gene annotations refer to the human genome build hg18. Of 8,842 individuals in KARE, 1,853 having missing values found in at least one of traits were removed. The individuals were described by a total of 52 traits (see Additional file 1), of which six traits (CRP, AST, ALT, r_gtp, homa, creatin) extremely distributed were removed. The resulting 6,998 individuals with 46 traits were employed in association rule mining.

\section{Association rule mining}

The problem of discovery of multivariate phenotypes from a set of single traits is transformed into finding 
frequent patterns of associations of single traits. In our approach we employed Association Rule Mining (ARM) [16] to discover the patterns of phenotypic associations expressed as association rules. We have previously shown $[14,17]$ that association rules detected by ARM are informative and quantitative and have benefits to interpret their meaning. Association rules have the form $\mathrm{R}: \mathrm{X} \rightarrow \mathrm{Y}[\mathrm{c}, \mathrm{s}]$, where $\mathrm{X}$ (the Left-hand side or LHS) and $Y$ (the Right-hand side or RHS) are the body and the head of a rule, respectively. $\mathrm{c}$ and $\mathrm{s}$ stand for confidence and support to measure accuracy of rules. $X$ and $\mathrm{Y}$ are disjoint predicates $(\mathrm{X} \cap \mathrm{Y}=\varnothing)$. Each $\mathrm{X}$ and $\mathrm{Y}$ consists of a conjunction of distinct predicates which describe values of single traits. An association rule expresses association of single traits $\mathrm{X}$ and $\mathrm{Y}$ and can be derived to a multivariate phenotype.

The strength of the association rules can be measured in terms of their support (s) and confidence (c). The support of a rule $(\mathrm{X} \rightarrow \mathrm{Y})$ is the probability that cases in a database contain both $\mathrm{X}$ and $\mathrm{Y}$. The confidence of a rule is the probability that cases contain $X$ can also contain Y. Note that the head of a rule, Y, is restricted to be one of the single traits which we are interested in and $\mathrm{X}$ is a set of traits partially correlated with Y. Interesting rules are manually extracted.

\section{Discovery of multivariate phenotypes}

\section{Association rule generation and post filtering the rules}

We used 10g Oracle Data Miner (ODM) which implemented the APRIORI algorithm [16] to compute association rules. We set a minimum support and a minimum confidence of $1 \%$ and $10 \%$, respectively, to detect rare patterns representing disease predisposing cases more rather common features appeared in normal cases.

If we set threshold too high for support (e.g., $20 \%$ ), there may miss many interesting patterns involving the low support with high confidence. Such low support traits may correspond to rare associations of sing traits, but whose patterns are still interesting to know. Most patterns mined characterize common correlations between traits, which are already well known. Domain experts such as biologists may have different interesting traits. Our strategy to find interesting rules is that we set low support threshold, generate as many rules and filter them by user interestingness measurements and interesting traits as user constraints. High confidence rules can misinform and do not consider the support of the traits appearing in the rule head. One way to resolve this problem is to apply a metric known as lift [18]:

$$
\text { Lift }=P(X, Y) / P(X) \times P(Y)
$$

which calculates the ratio between the rule's confidence and support of the single trait $Y$ in the rule consequence. Lift was originally called interest which measures how many times more often $X$ and $Y$ occur together than expected if they are statistically independent.

The following example shows rule form constraints to find interesting association rules containing single traits such as high levels of TG (TG5) and low levels of LDL (LDL1):

R1: $((\mathrm{TG} 5 \subset \mathrm{LHS}) \vee(\mathrm{TG} 5 \subset \mathrm{RHS})) \wedge($ min_conf $\geq 0.7$, lift $\geq 1$, min_sup $\geq 0.025)$,

R2: $(($ LDL1 $\subset$ LHS $) \vee($ LDL1 $\subset$ RHS $)) \wedge($ min_conf $\geq 0.7$, lift $\geq 1$, min_sup $\geq 0.025$ ).

\section{Visualization of phenotypic association}

We employed graph-based techniques to visualize interesting association rules using igraph package on $\mathrm{R}$ 2.12.0. A set of interest association rules represented with an undirected edge weighted graph where vertices represent traits and edges indicate relationships (i.e. associations) between other traits in rules. Vertex size is proportional to degrees of vertices.

\section{A scheme of association analysis \\ An algorithm for association test}

A multivariate phenotype(y) is defined as bivariate traits $\left(y_{i}, y_{j}\right)$ which can be a mixture of continuous and nominal traits. The multivariate phenotype can be a conjunction of predicates of single traits, as expressed one or more association rules.

$$
\mathrm{y}=\mathrm{y}_{\mathrm{i}}+\mathrm{y}_{\mathrm{j}}
$$

Association analysis for multivariate phenotype(y) is performed by following tasks:

(1) Test a genome-wide scan for a multivariate phenotype (y): GWAS(y)

(2) Test genome-wide scans for singleton traits: $\operatorname{GWAS}\left(\mathrm{y}_{\mathrm{i}}\right), \operatorname{GWAS}\left(\mathrm{y}_{\mathrm{j}}\right)$

(3) Calculate $\mathrm{mOR}_{\mathrm{p}}{ }^{\mathrm{s}}$ where minus log odds ratio for p-values of SNPs obtained from an association test of a multivariate phenotype(y) over those from a single trait $\left(\mathrm{y}_{\mathrm{i}}\right)$ as follows:

$$
m O R_{p}{ }^{\gamma i}=-\log _{10}\left(\operatorname{Pvalue}(\gamma) / \operatorname{Pvalue}\left(y_{i}\right)\right)
$$

(4) Prune SNPs by filtering strategies (see section strategy for pruning SNPs)

(5) Repeat tasks 2 4 for other single trait $\left(y_{\mathrm{j}}\right)$

(6) A final set of SNPs is generated by the intersection of two sets of SNPs survived from filtering steps which prune SNPs more likely to affect either of single traits.

SNPs identified for an association test of a multiple phenotype may include genetic variants more likely affecting each of single traits which should be excluded. Tasks 1 to 4 are subject to filtering steps to identify genetic variants influencing the multivariate phenotype $y$ while the genetic variants much more likely to affect single traits $\left(y_{i}\right.$ and $y_{j}$ ) are excluded by $\mathrm{mOR}_{\mathrm{p}}{ }^{\mathrm{S}}$ (vide 
infra). The $\mathrm{mOR}_{\mathrm{p}}{ }^{\mathrm{S}}$ measures the strength of association of a multivariate phenotype against those of single traits.

\section{Strategy for pruning SNPS}

From a list of results of the association test for a multivariate phenotype, false positives of SNPs are pruned by the following conditions and significant ones remain:

(1) P-values for an association test of multivariate phenotype $\leq 5 \times 10^{-4}$

(2) $\mathrm{mOR}_{\mathrm{P}}{ }^{\mathrm{yi}} \geq 1$ and $\mathrm{mOR}_{\mathrm{p}}{ }^{\mathrm{yj}} \geq 1$

(3) $\mathrm{P}$-value of an indexed $\mathrm{SNP} \leq 10^{-5}$ and $\mathrm{p}$-values of clumped SNPs $\leq 10^{-4}$ in order to evaluate formation of LD.

There have been no generalized method to deal with the multivariate phenotypes and the cut-off $\mathrm{p}$-value for a significant association in GWAS is not well defined. The cut-off $p$-value for the multivariate phenotype is set to be less stringent than usual GWAS which mostly set a Bonferroni corrected p-value of $0.05\left(\mathrm{P} \leq 1.43 \times 10^{-7}\right.$ which is not corrected) since we consider a small sample size for cases and controls due to combination of phenotypes. $\mathrm{mOR}_{\mathrm{P}}{ }^{\mathrm{S}} \geq 1$ means that it is 10 times as likely that SNPs are associated with a multivariate phenotype against a single one.

\section{Application to GWAS of lipid levels}

We applied to multivariate phenotype based GWAS to relations between plasma lipid levels for an in-depth study. Positive relations between TG and LDL-C can be specified as multivariate phenotype highLDLhighTG, which indicates high LDL-C of $\geq 130 \mathrm{mg} / \mathrm{dl}$ and high TG of $\geq 180 \mathrm{mg} / \mathrm{dl}$ extracted from 359 rules. Ranges of
TG and LDL-C levels for GWAS are adjusted for those meeting the guidelines used in clinical researches.

An association test of highLDLhighTG seeks to identify single shared loci affecting both high levels of LDL$\mathrm{C}$ and TG while excluding ones affecting either of the single traits LDL-C and TG. 545 cases and 680 controls (Table 1 and see Additional file 2 for single traits) are selected for GWAS of multivariate phenotype highLDLhighTG. SNPs influencing on either one of TG or LDL-C traits were pruned from a list of significant SNPs associated with highLDLhighTG. Case-control based association scans and LD clumping were performed by PLINK [19].

\section{Results and discussion}

\section{Multiple phenotypic associations}

Out of a total 3,792,566 rules mined, 765,318 rules of which lift $\geq 1$ and confidence $\geq 0.5$ were retained. 136,551 rules encoded TG and LDL levels. Of 19,837 rules related to high TG levels, 191 interesting rules represent low LDL-C and high TG in contrast to 509 rules that manifested high TG and high LDL-C levels. Table 2 denotes the representative association rules (see Additional file 3) and interpretation of rules refer to the previous work [14].

\section{Associations between high TG levels and MS related traits}

Association patterns of single traits extracted from 359 rules containing high TG levels were visualized by a connected graph (Figure 1). High TG trait ( TG5 in Figure 1) connected with peculiar nodes representing the 17 distinctive traits: Bone Mineral Density (BMD)

Table 1 Descriptive summary of samples

\begin{tabular}{|c|c|c|c|c|c|c|c|c|}
\hline \multirow{2}{*}{$\begin{array}{l}\text { highLDL highTG } \\
\text { Area/sex } \\
\text { n=individual }\end{array}$} & \multicolumn{4}{|c|}{ Control $(\mathrm{LDL} \leq 100$ and $\mathrm{TG} \leq 100, \mathrm{n}=681)$} & \multicolumn{4}{|c|}{ Case $(\mathrm{LDL} \geq 130$ and $\mathrm{TG} \geq 180, \mathrm{n}=545)$} \\
\hline & Ansung $n=381$ & $\begin{array}{l}\text { Ansan } \\
n=300\end{array}$ & Male $n=233$ & Female $n=458$ & $\begin{array}{l}\text { Ansung } \\
n=205\end{array}$ & Ansan $n=340$ & Male $n=288$ & Female $n=257$ \\
\hline AGE & $52.6 \pm 9.45$ & $45.7 \pm 5.88$ & $54.1 \pm 9.34$ & $47.3 \pm 7.56$ & $56.6 \pm 8.20$ & $50.1 \pm 8.19$ & $49.6 \pm 7.99$ & $55.8 \pm 8.45$ \\
\hline $\mathrm{BMl}$ & $22.7 \pm 3.06$ & $23.2 \pm 2.80$ & $21.8 \pm 2.71$ & $23.4 \pm 2.94$ & $26.0 \pm 2.84$ & $25.9 \pm 2.71$ & $25.5 \pm 2.58$ & $26.4 \pm 2.89$ \\
\hline WHR & $0.88 \pm 0.06$ & $0.79 \pm 0.07$ & $0.87 \pm 0.06$ & $0.83 \pm 0.08$ & $0.95 \pm 0.05$ & $0.87 \pm 0.05$ & $0.90 \pm 0.05$ & $0.90 \pm 0.08$ \\
\hline $\mathrm{TCHL}$ & $148 \pm 18.3$ & $151 \pm 15.61$ & $149 \pm 17.8$ & $150 \pm 16.9$ & $240 \pm 22.3$ & $243 \pm 24.6$ & $242 \pm 22.8$ & $242 \pm 24.9$ \\
\hline $\mathrm{HDL}$ & $50.3 \pm 10.5$ & $50.0 \pm 10.5$ & $51.0 \pm 12.0$ & $49.8 \pm 9.70$ & $42.4 \pm 8.56$ & $42.5 \pm 7.66$ & $42.2 \pm 7.55$ & $43.0 \pm 8.48$ \\
\hline LDL & $81.8 \pm 14.8$ & $85.1 \pm 11.7$ & $81.6 \pm 14.5$ & $84.1 \pm 13.1$ & $150 \pm 16.8$ & $155 \pm 20.9$ & $152 \pm 18.6$ & $153 \pm 20.7$ \\
\hline TG & $81.4 \pm 13.4$ & $81.0 \pm 12.4$ & $80.9 \pm 14.5$ & $81.4 \pm 12.2$ & $238 \pm 51.7$ & $231 \pm 49.0$ & $237 \pm 52.3$ & $230 \pm 47.3$ \\
\hline highLDL & \multicolumn{4}{|c|}{ Control $(\mathrm{LDL} \leq 100, \mathrm{n}=2215)$} & \multicolumn{4}{|c|}{ Case $(\mathrm{LDL} \geq 130, \mathrm{n}=2271)$} \\
\hline $\begin{array}{l}\text { Area/sex } \\
\mathrm{n}=\text { individual }\end{array}$ & $\begin{array}{l}\text { Ansung } \\
n=1403\end{array}$ & $\begin{array}{l}\text { Ansan } \\
n=812\end{array}$ & $\begin{array}{c}\text { Male } \\
n=1024\end{array}$ & $\begin{array}{l}\text { Female } \\
n=1191\end{array}$ & $\begin{array}{c}\text { Ansung } \\
n=919\end{array}$ & $\begin{array}{c}\text { Ansan } \\
n=1352\end{array}$ & $\begin{array}{c}\text { Male } \\
n=1044\end{array}$ & $\begin{array}{l}\text { Female } \\
n=1227\end{array}$ \\
\hline LDL & $79.6 \pm 16.6$ & $84.1 \pm 12.4$ & $79.2 \pm 17.3$ & $83.0 \pm 13.2$ & $151 \pm 17.9$ & $155 \pm 20.9$ & $154 \pm 19.5$ & $153 \pm 20.1$ \\
\hline TG & $157 \pm 78.5$ & $148 \pm 78.0$ & $169 \pm 82.2$ & $140 \pm 72.5$ & $146 \pm 61.8$ & $147 \pm 61.3$ & $152 \pm 65.3$ & $142 \pm 57.6$ \\
\hline highTG & \multicolumn{4}{|c|}{ Control $(T G \leq 100, n=1914)$} & \multicolumn{4}{|c|}{ Case $(T G \geq 180, \mathrm{n}=1779)$} \\
\hline $\begin{array}{l}\text { Area/sex } \\
\mathrm{n}=\text { individual }\end{array}$ & Ansung $n=920$ & $\begin{array}{l}\text { Ansan } \\
n=994\end{array}$ & Male $n=700$ & $\begin{array}{l}\text { Female } \\
n=1214\end{array}$ & $\begin{array}{c}\text { Ansung } \\
n=936\end{array}$ & Ansan $n=843$ & Male $n=969$ & Female $n=810$ \\
\hline LDL & $109 \pm 29.7$ & $118 \pm 30.0$ & $116 \pm 31.9$ & $112 \pm 29.1$ & $104 \pm 33.7$ & $122 \pm 33.8$ & $111 \pm 35.8$ & $115 \pm 33.8$ \\
\hline TG & $81.4 \pm 13.6$ & $80.4 \pm 13.5$ & $80.0 \pm 14.8$ & $81.5 \pm 12.7$ & $248 \pm 55.5$ & $241 \pm 53.6$ & $248 \pm 56.1$ & $240 \pm 52.6$ \\
\hline
\end{tabular}


Table 2 Representative association rules

\begin{tabular}{|c|c|c|c|c|c|c|}
\hline $\begin{array}{c}\text { Rule } \\
\#\end{array}$ & Rule body & & Rule head & Supp & Conf & Lift \\
\hline \multicolumn{7}{|c|}{ Rules encoding highTG levels } \\
\hline 1 & LDL5, BMI5, TG5, TCHL5 & $\rightarrow$ & NONHDL5 & 0.0157 & 1.0000 & 5.1732 \\
\hline 2 & $\begin{array}{c}\text { GLU1205, TCHL5, LDL5, } \\
\text { TG5 }\end{array}$ & $\rightarrow$ & NONHDL5 & 0.0136 & 1.0000 & 5.1732 \\
\hline 3 & $\begin{array}{c}\text { LDL5, TG5, TCHL5, } \\
\text { GLU05 }\end{array}$ & $\rightarrow$ & -5 & 32 & 1.0 & 5.1732 \\
\hline 4 & $\begin{array}{l}\text { TG5, PLAT5, LDL5, } \\
\text { NONHDL5 }\end{array}$ & $\rightarrow$ & & 27 & 1.0000 & 5.1465 \\
\hline 5 & $\begin{array}{l}\text { GLU605, TG5, TCHL5, } \\
\text { LDL5 }\end{array}$ & $\rightarrow$ & L5 & 26 & 1.0000 & 5.1732 \\
\hline 6 & TG5, LDL5, TCHL5, DS1 & $\rightarrow$ & L5 5 & 0.0122 & 1.0000 & 5.1732 \\
\hline 7 & $\begin{array}{c}\text { LDL5, INS1205, TCHL5, } \\
\text { TG5 }\end{array}$ & $\rightarrow$ & L5 & 19 & 1.0 & 5.1732 \\
\hline 8 & DBP5, TG5, LDL5, TCHL5 & $\rightarrow$ & LL5 & 0.0119 & 1.0000 & 5.1732 \\
\hline 9 & $\begin{array}{l}\text { INS605, TCHL5, TG5, } \\
\text { LDL5 }\end{array}$ & $\rightarrow$ & L5 & 0.0116 & 1.0000 & 5.1732 \\
\hline 10 & TG5, TCHL5, INS05, LDL5 & $\rightarrow$ & DL5 & 0.0107 & 1.0000 & 5.1732 \\
\hline 11 & TG5, LDL5, SBP4, TCHL5 & $\rightarrow$ & NONHDL5 & 0.0107 & 1.0000 & 5.1732 \\
\hline 12 & TG5, TCHL5, WHR5, LDL5 & $\rightarrow$ & NONHDL5 & 0.0107 & 1.0000 & 5.1732 \\
\hline 13 & $\begin{array}{c}\text { T_HDL5, NONHDL5, } \\
\text { LDL4, HDL2 }\end{array}$ & $\rightarrow$ & & 0.0102 & 0.8875 & 4.1105 \\
\hline 14 & $\begin{array}{c}\text { TCHL2, LDL1, NONHDL2, } \\
\text { PH1 }\end{array}$ & $\rightarrow$ & TG5 & 0.0100 & 0.8333 & 3.8595 \\
\hline \multicolumn{7}{|c|}{ Rules encoding highLDL levels } \\
\hline 15 & $\begin{array}{l}\text { TCHL5, NONHDL5, } \\
\text { GLU605 }\end{array}$ & $\rightarrow$ & LDL5 & 0.0405 & 0.8324 & 4.2651 \\
\hline 16 & DS1, NONHDL5, GLU605 & $\rightarrow$ & LDL5 & 0.0155 & 0.8182 & 4.1924 \\
\hline 17 & $\begin{array}{c}\text { NONHDL5, SONA4, } \\
\text { TCHL5 }\end{array}$ & $\rightarrow$ & LDL5 & 0.0242 & 0.8450 & 4.3297 \\
\hline 18 & TG3, BUN5, NONHDL5 & $\rightarrow$ & LDL5 & 0.0114 & 1.0000 & 5.1239 \\
\hline
\end{tabular}

Definition of trait names refers to Figure 1 .

measure, distal radius SOS(DS); Blood components, $\mathrm{HB}$, WBC_B, PLAT, and HBA1C; and metabolic syndrome (MS) (Daskalopoulou, et al., 2006) measures, obesity (BMI, WHR and SUP), lipids (LDL, HDL, TCHL, T_HDL, TG and NONHDL), hypertension (SBP and DBP) and insulin resistance (GLU0, INS0, GLU60 and GLU120), post-challenge insulin(INS60 and INS120). The abbreviation of single traits refers to Figure 1.

Associations between high TG levels and a cluster of 4 common traits (obesity, insulin resistance, hypertension, and hyperlipidemia) related to MS, were consistent with the fact that MS increases T2D and cardiovascular diseases (CVD) [20].

\section{Associations between high TG levels and BMD}

One of the noteworthy findings is the association between low DS for the measure of BMD and high TG levels. The associations between low DS and a cluster of MS defined by the four common traits i.e. obesity, hypertension, hyperlipidemia and insulin resistance with high glucose levels and dissociation with insulin levels (INS0, INS60, INS120) were in concordance with newly reported work [21] that examined an association between MS and bone health. There are negative relations between low DS associated with high levels of lipids including TG, TCHL and LDL and positive relations between low DS with low levels of HDL [22]. More interesting finding was observed in that low DS are associated with high levels of glucose but not with insulin levels although the association between high glucose levels or insulin resistance with BMD has been inconclusive. In contrast, hyperglycemia is known for a predictor of bone loss and osteoporotic fractures [23]. Our finding can be a suggestive evidence that obesity, hypertension and hyperlipidemia among MS related traits might be associated with osteoporosis.

\section{Associations with high LDL}

High levels of LDL were shown positive relations with BMI, glucose levels and plasma lipids including TCHL, TG, and NONHDL as well as negative relations with DS. We did not find associations between high LDL levels and insulin levels. Interestingly, highLDL have positive relations with single traits related to renal function such as Blood Urea Nitrogen (BUN) and Sodium in Urine (SONA).

\section{Pattern of multivariate phenotype highLDLhighTG}

Among multiple phenotypic associations with high TG, we considered the phenotypic associations which subdivided samples into feasible sizes of cases and controls for GWAS. We focused on contradictory relationship between high TG levels (TG5 in Figure 1(a)) with low or high levels of LDL (LDL1 in Figure 1(a) and LDL5 in Figure 1(b)). That is, there are positive correlations: between TG and LDL-C and TCHL; between LDL-C and HDL as well as negative correlations: between TG and LDL-C; between HDL and TG, LDL-C and TCHL. Both single traits, high TG levels and high LDL levels, shared common traits (BMI, PLAT, TCHL, and GLUO) associated with themselves.

Combination of two single traits, high LDL and high TG, introduces multivariate phenotype highLDLhighTG which can amplify association strength with correlated single traits by additive effects of the single traits. Out of 17 associated traits, four traits (DS, GLU0, INS0, and SONA) have more power in distinctively classifying samples of highLDLhighTG into cases and controls (Figure 2).

The associations between the traits can be substantiated in association rules encoding high TG levels (Rules 1 14) and high LDL-C levels (Rules 15-18). The rules were sorted and selected by their confidences.

As seen from above, there exist complicated associations among single traits. Selection of cases and controls based on single traits without considering those associations may increase confounding effects in samples. Compared with single traits based selection of cases and 


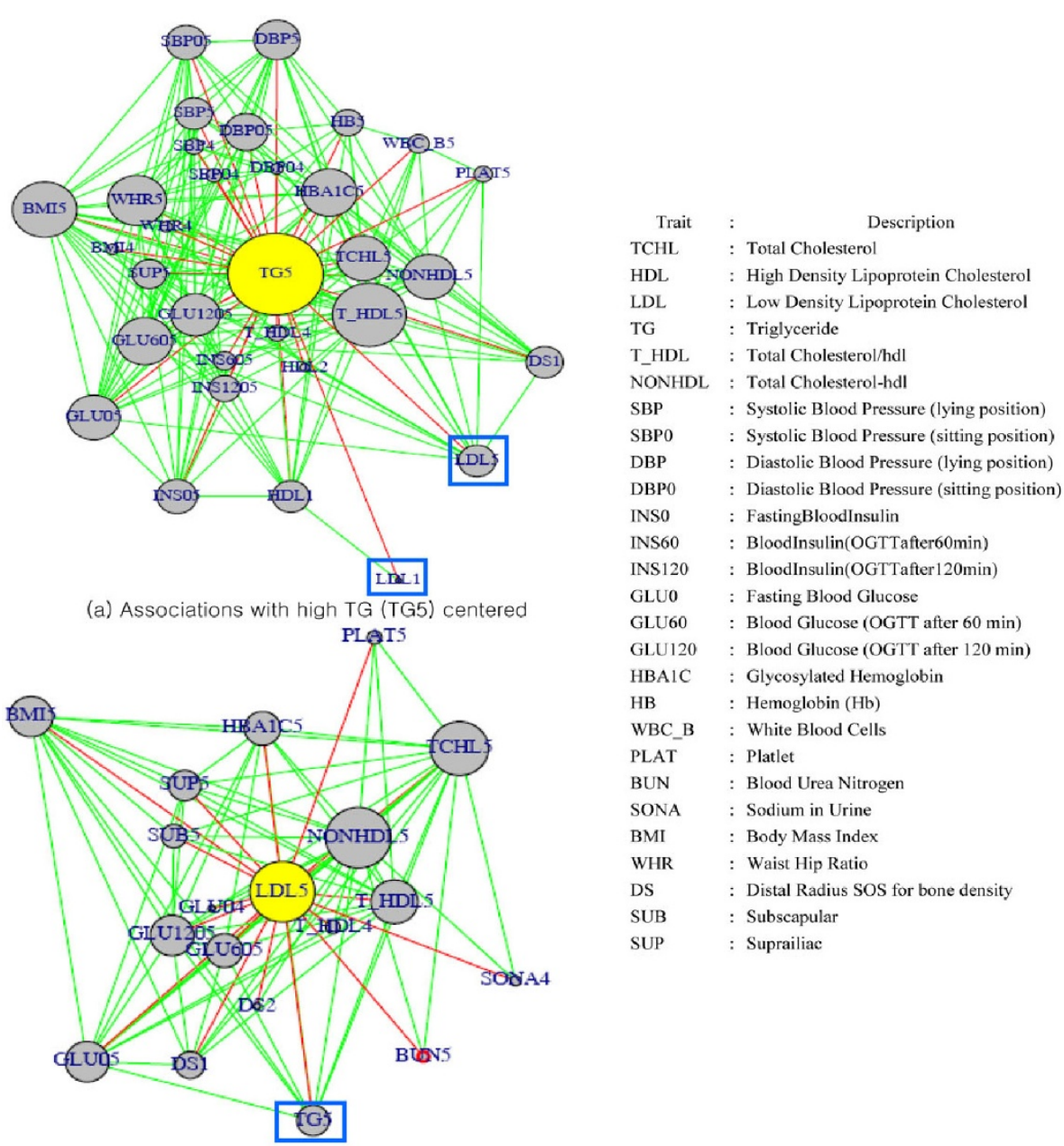

(b) Associations with high LDL (LDL5) centered

Figure 1 Visualization of phenotypic associations with connected graphs.

controls, multivariate based approach can have more power to distinguish cases from controls.

\section{GWAS results of Plasma lipid levels}

We identified total 50 variants associated with highLDLhighTG and 15 are located in six genes (PAK7, C20orf103, NRIP1, BCL2, TRPM3, and NAV1) (Table 3 and Figure 3). It is interesting to know that rs11700112 of $P A K 7$ on 20p12.2 is in a missense mutation by substitution of arginine (CGA) by proline (CCA). Clinical association has not yet been found with this variant. It is located within a LD block $(530 \mathrm{~kb})$ with other four SNPs, of which two (rs6140956 and rs6133716) are in intronic region of C20orf103. It is worth to note that C20orf103 contains a frameshift mutation at rs72238296, which is 755 bases upstream of rs6140956 in the same gene (Table. 3 and Figure 4(a)). The frameshift mutation is known for a cause of a hypercholesterolemia [24].
A strong LD block (81kb length) with high $\mathrm{r}^{2}$ values $\left(r^{2} \geq 0.90\right)$ detected across three SNPs (rs4744611, rs7039780 and rs4744608) (Figure 5(b)) of TRPM3 on chromosome 9 (9q21.11-q21.12) that is relatively close to regions linked to coronary artery disease [25]. Among nine splice variants of TRPM3, splice variants 7 and 8 do not include the three SNPs identified (Figure 5(a)). This observation suggests that SNPs can make different functional effects on splice variants. Although no firm genetic linkage to disease has been established and not much report on the properties of TRPM3, functional activity of TRPM3 is relevant to contractile and proliferating vascular smooth muscle cells. Recent work [26] investigated the relevance and regulation of TRPM3 in vascular biology and showed that elevated cholesterol can act as a negative regulator of TRPM3.

Two SNPs of BCL2 gene on chromosome 18 (18q21.33) were identified. BCL2, which is involved in a number of cancers including melanoma, breast 


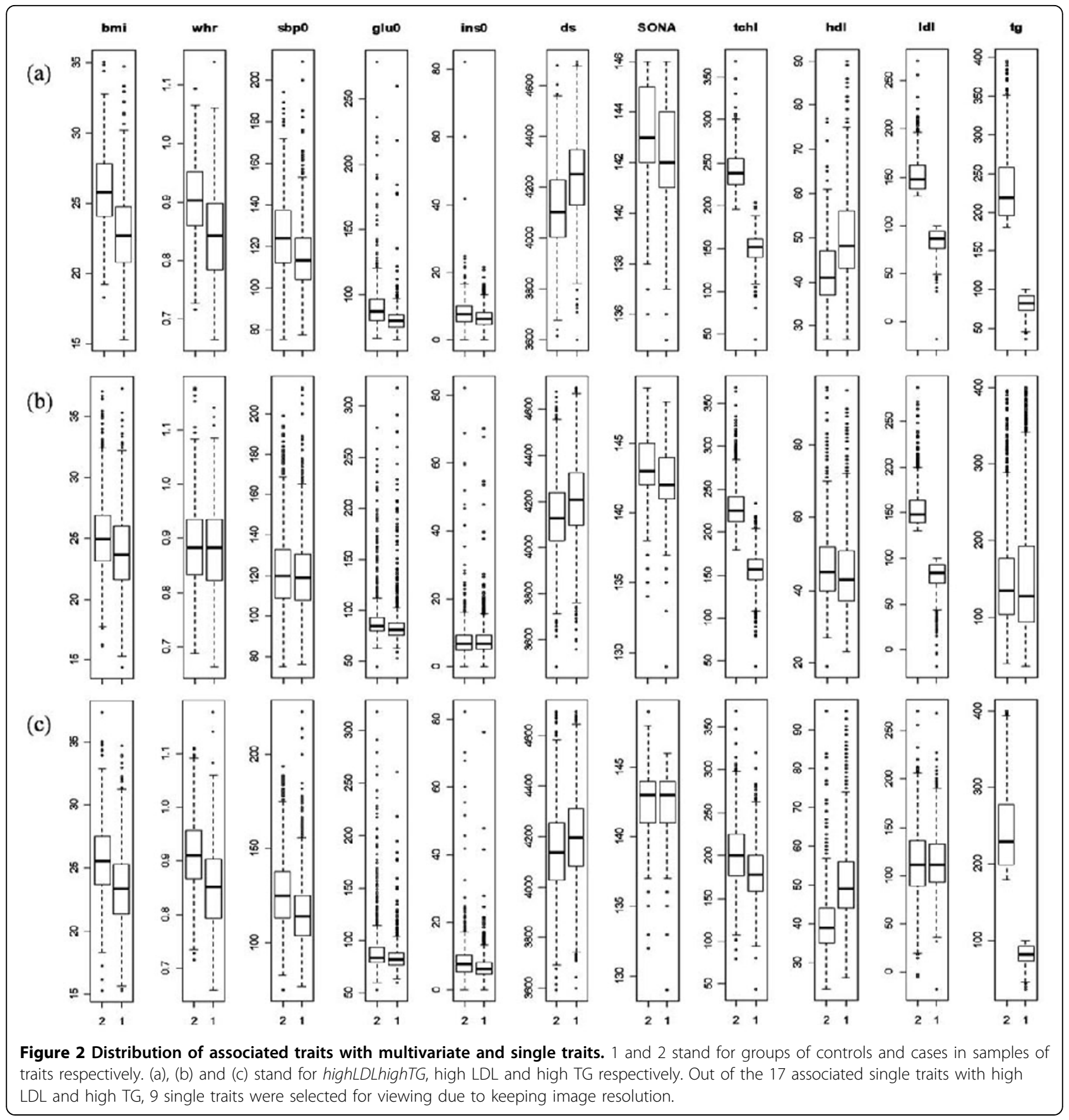

carcinomas and etc., was recognized as important modulators of cardiac myocyte apoptosis. A distinct support for relevance of $B C L 2$ to cardio vascular disease (CVD) was reported by recent finding [27] that PPAR $\gamma$ protected cardiac myocytes from oxidative stress and apoptosis through upregulating BCL2 expression.

NRIP1 was reported to have an association with HDL [28]. Recent studies identified a hepatocyte specific role for NRIP1 as a cofactor for $L X R$ in different ways, namely serving as a coactivator in lipogenesis and as a corepressor in gluconeogenesis [29]. NAV1 on chromosome 1q32.1, a human homolog of a C. elegans gene, unc-53, is expressed in adult heart and the developing brain. Clinical association has not been established with it. Our results warrant that variants associated with highLDLhighTG should be evaluated for further study.

It is important to emphasize that LD structures for the six genes across three populations (YRI, CEU, JPT $+\mathrm{CHB})$ are distinct. The pattern of the strongest LD was observed in $\mathrm{JPT}+\mathrm{CHB}$ among the three. Whereas, the 
Table 3 Genetic variants associated with highLDLhighTG

\begin{tabular}{|c|c|c|c|c|c|c|c|c|c|c|c|c|c|}
\hline SNP & Chr & Base position & SNP type & gene & Str- and & Alle & $+/-)$ & Freq $(+)$ & P-value hLDLhTG & OR & $\mathrm{mOR}_{\mathrm{p}}{ }^{\mathrm{LDL}}$ & $\mathrm{mOR}_{\mathrm{p}}{ }^{\mathrm{TG}}$ & $r^{2}$ \\
\hline rs11700112 & 20 & 9495018 & nonsyn & PAK7 & - & $G$ & $C$ & 0.31 & $6.2 \times 10^{-5}$ & 1.44 & 3.25 & 1.58 & 1.00 \\
\hline rs6140956 & 20 & 9450080 & intronic & C20orf103 & + & C & $\mathrm{T}$ & 0.41 & $6.3 \times 10^{-5}$ & 1.40 & 2.79 & 1.85 & 0.56 \\
\hline rs6133716 & 20 & 9455931 & intronic & C20orf103 & + & $A$ & G & 0.40 & $1.0 \times 10^{-4}$ & 1.39 & 2.58 & 1.75 & 0.59 \\
\hline rs9967942 & 20 & 9503781 & intronic & PAK7 & - & $C$ & A & 0.34 & $9.6 \times 10^{-5}$ & 1.41 & 3.24 & 1.76 & 0.89 \\
\hline rs11087847 & 20 & 9504159 & intronic & PAK7 & - & $\mathrm{T}$ & G & 0.31 & $8.6 \times 10^{-5}$ & 1.43 & 3.02 & 1.59 & 0.99 \\
\hline rs2822994 & 21 & 15282928 & intronic & NRIP1 & - & $A$ & G & 0.41 & $8.7 \times 10^{-5}$ & 1.40 & 2.46 & 2.59 & 1.00 \\
\hline rs2822998 & 21 & 15285230 & intronic & NRIP1 & - & C & A & 0.41 & $4.1 \times 10^{-4}$ & 1.35 & 2.09 & 2.12 & 0.97 \\
\hline rs1041404 & 21 & 15346738 & intronic & NRIP1 & - & $A$ & G & 0.43 & $1.7 \times 10^{-4}$ & 1.37 & 2.38 & 2.33 & 0.64 \\
\hline rs9959874 & 18 & 59045526 & intronic & $\mathrm{BCL} 2$ & - & A & G & 0.15 & $1.2 \times 10^{-4}$ & 1.60 & 3.40 & 2.20 & 1.00 \\
\hline rs1893506 & 18 & 59044660 & intronic & $\mathrm{BCL2}$ & - & G & A & 0.15 & $1.5 \times 10^{-4}$ & 1.59 & 3.31 & 2.08 & 1.00 \\
\hline rs4744611 & 9 & 72551280 & intronic & TRPM3 & - & G & A & 0.49 & $1.8 \times 10^{-4}$ & 1.36 & 1.93 & 3.14 & 1.00 \\
\hline rs7039780 & 9 & 72469777 & intronic & TRPM3 & - & G & A & 0.50 & $3.7 \times 10^{-4}$ & 1.34 & 1.57 & 2.98 & 0.90 \\
\hline rs4744608 & 9 & 72470797 & intronic & TRPM3 & - & G & C & 0.50 & $3.7 \times 10^{-4}$ & 1.34 & 1.52 & 2.99 & 0.90 \\
\hline rs665770 & 1 & 200014747 & intronic & NAV1 & + & $A$ & G & 0.38 & $2.0 \times 10^{-4}$ & 1.38 & 2.65 & 1.54 & 1.00 \\
\hline rs529581 & 1 & 200016143 & intronic & NAV1 & + & $C$ & G & 0.37 & $2.0 \times 10^{-4}$ & 1.38 & 2.59 & 1.59 & 0.99 \\
\hline rs693 & 2 & 21085700 & coding & APOB & - & $A$ & G & 0.07 & $7.3 \times 10^{-4}$ & 1.83 & 0.04 & 2.21 & - \\
\hline
\end{tabular}

SNP rs693 reported in a previous study (Kathiresan, et al, 2008) for associations between high TG and high LDL. The rs693 was pruned since its effect was stronger in single traits high LDL than multivariate highLDLhighTG with borderline significance.

weak pattern of LD was appeared to be in CEU (see Additional file 4).

\section{In silico replication}

In silico replication analysis was conducted for the 15 SNPs in two regional subcohorts as well as gender groups (Table 4). Nine of 15 SNPs associated with highLDLhighTG were well reproducible in regional subcohorts $(\mathrm{P}<0.05)$, while $\mathrm{p}$-values of six SNPs $(\mathrm{p} \geq 0.05)$ were on the borderline statistical significance. Five SNPs in NIRP1 (rs2822994, rs2822998 and rs1041404) and NAVI (rs665770 and rs529581) were more reproducible in both regional subcohorts and gender groups.
Reproducibility of gender difference in the 15 SNPs were as follows: PAK7 and NRIP1 were more effective in women; BCL2, TRPM3 and NAV1 were more reproducible in men. highLDLhighTG was more detectable in women than $\operatorname{man}\left(\chi^{2} \geq 44.9\right.$, p-value $\left.=2.05 \times 10^{-11}\right)$. PAK7 and NRIP1 may lead to the gender specific susceptibility in concordance with previous work [30] reporting more gender-specific effects for CVD in women than men.

\section{Comparison of general GWAS}

Overall distribution of $\mathrm{p}$-values for an association test appeared to be less significant than those for general

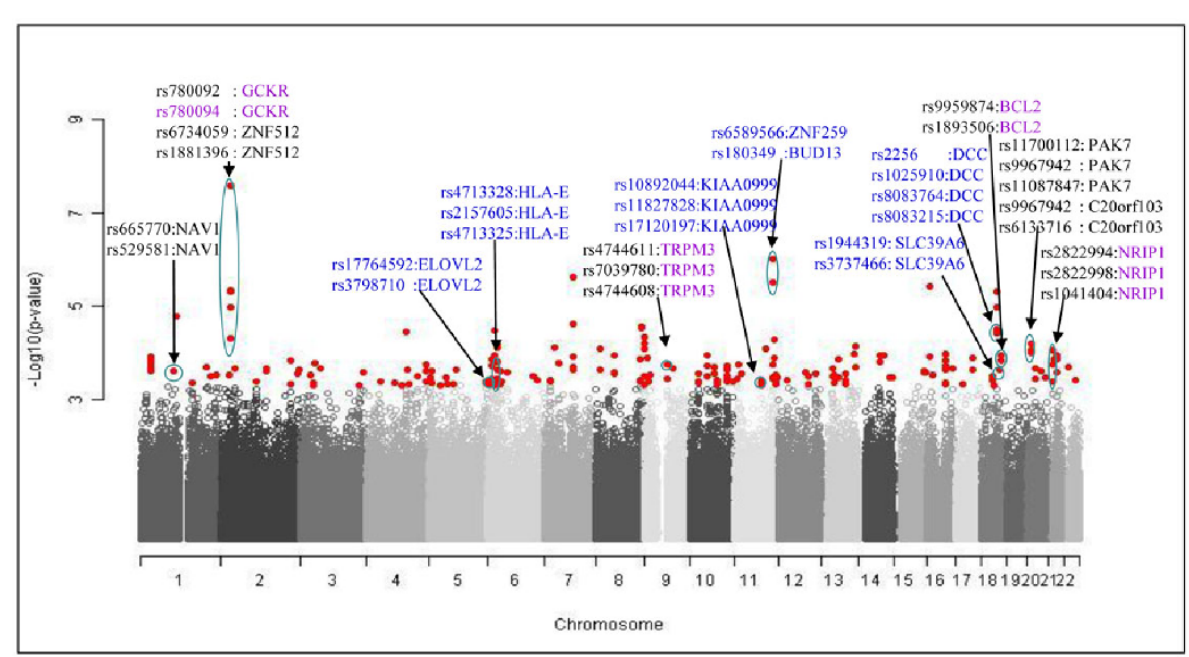

Figure 3 A manhattan plot for an association test of highLDLhighTG. Gene symbols in purple represents loci identified in previous GWAS of lipids (Kathiresan, et al., 2008). SNPs in blue were pruned. 


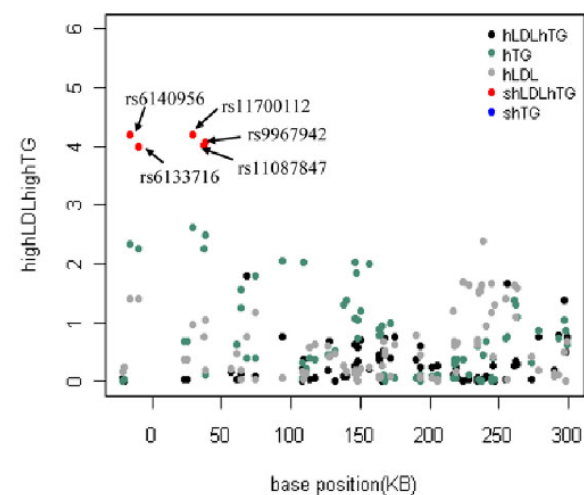

(a) C20orf103 and PAK7

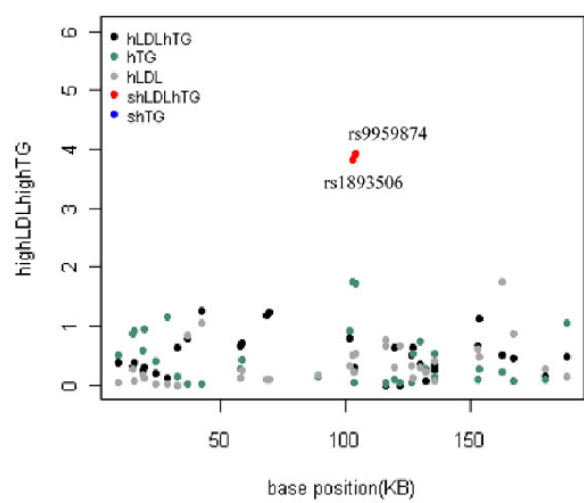

(c) BCL2

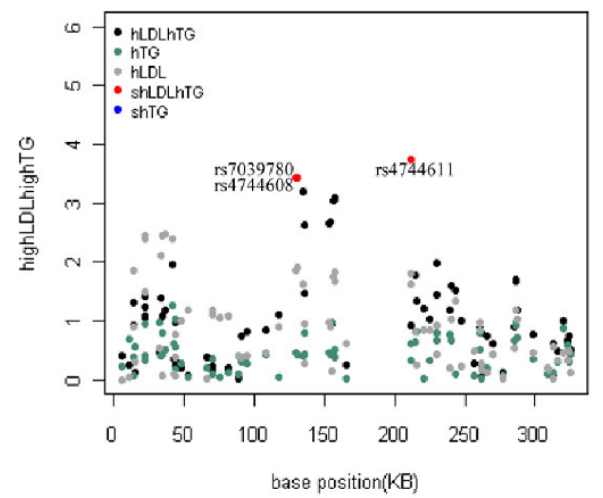

(b) TRPM3

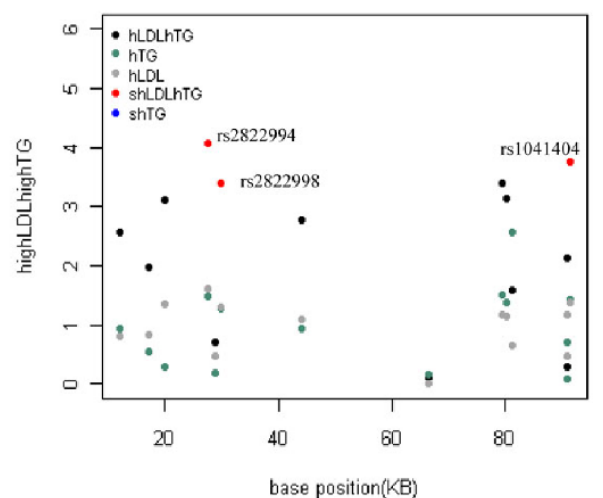

(d) NRIP1

Figure 4 P-value distributions of association tests for highLDLhighTG and single traits highTG and highLDL. Points in red are significantly identified SNPs in the association test of highLDLhighTG. highLDLhighTG is presented with $h L D L h T G$ and single traits highTG and highLDL are presented in $\mathrm{hTG}$ and $\mathrm{hLDL}$ respectively.

GWAS. On the other hand, the p-values of significant SNPs identified for multivariate phenotype highLDLhighTG were apparently more significant than those for single traits highLDL and highTG (Figure 6). It is noteworthy that effect sizes of the significant SNPs which ranged between modest (odds ratios $=1.38-1.60$ ) and intermediate effect sizes were comparable to those for the general GWAS ranged from low to modest ones.

\section{Pleiotropic patterns of quantitative trait loci}

Pleiotropic patterns can be more precisely observed in quantitative trait loci (QTLs) or LD blocks than at SNPs. We examined QTLs and their associated phenotypes for the six genes identified using Phenotype and Disease Association track group in UCSC genome browser. The QTLs and their associated phenotypes were extracted from rat and mouse QTLs from RAT DB and MGI (Mouse Genome Information) (Table 5).

The six genes except NRIP1 share QTLs commonly associated traits such as BMD and a cluster of common traits defining MS. Those common traits in MS shared by the six genes are blood pressure, non-insulin dependent diabetes mellitus, renal function, cardiac mass, and body weight. The phenotypic associations of high TG and high LDL levels with low BMD examined through rat and mouse QTL associations except NRIP1 have mapped in the regions of QTLs associated with BMD. Furthermore it can be more support that TRPM3 was mapped to OMIM phenotypes such as osteosclerosis hardening bones, epilepsy, amyotrophic lateral sclerosis (ALS), of which association with CVD was reported in a recent work [31]. Different genetic markers share the same or similar OMIM phenotypes: $B C L 2$ and TRPM3 have in common with associating ALS; PAK7 and $N A V 1$ have in common with similar phenotypes Alzheimer disease (AD) and Parkinson disease (PD) where a cross-talk between MS and AD was reported [32].

In summary, our results suggest that the genetic markers identified with multivariate phenotype highLDLhighTG have phenotypic associations with common traits in MS. The common traits in MS, particularly hyperlipidemia, may be linked to pathogenic associations with osteosclerosis and neurodegenerative disorders 


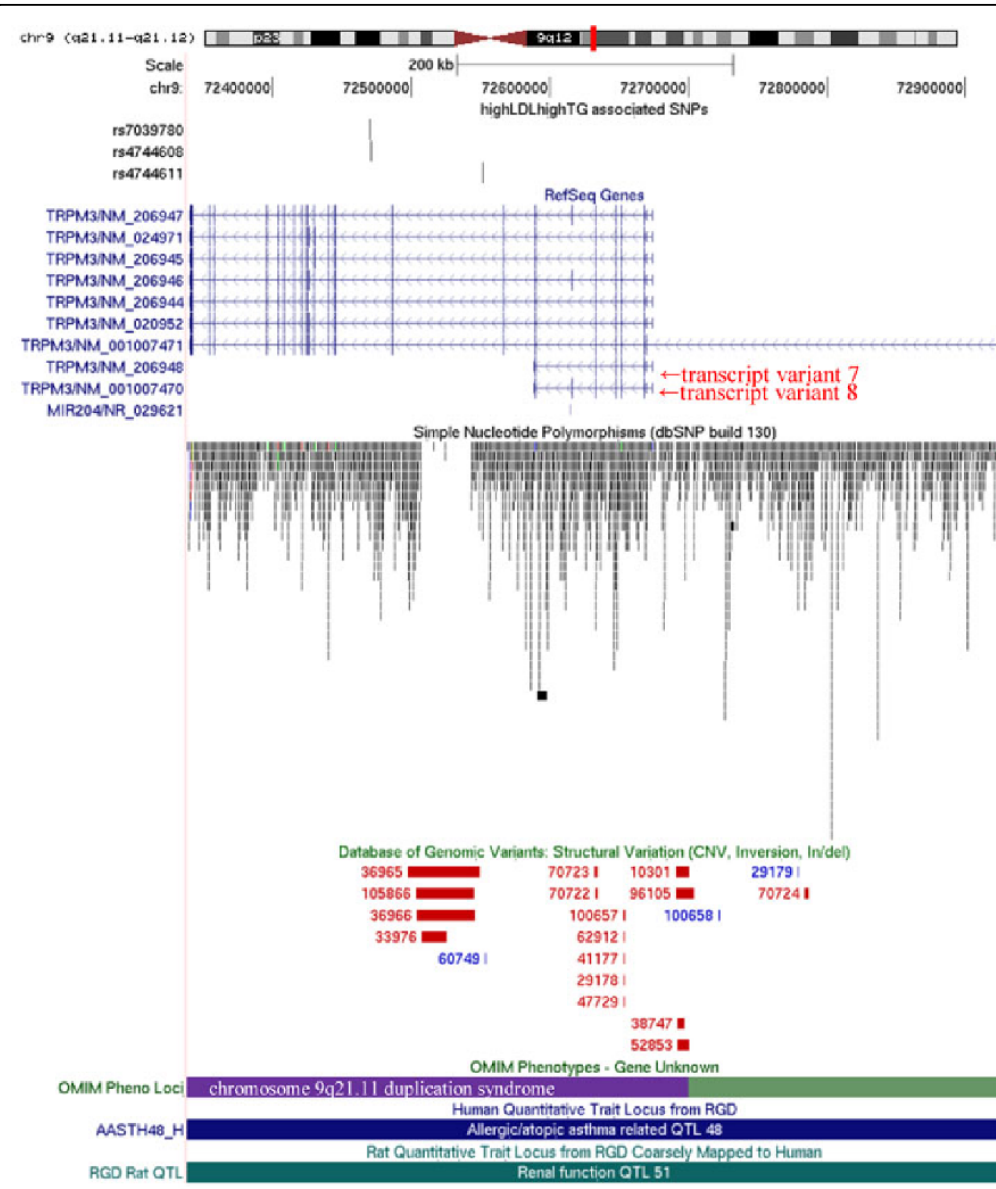

(a) Characteristics of genomic region (chr9:72,338,000-72,927,000)

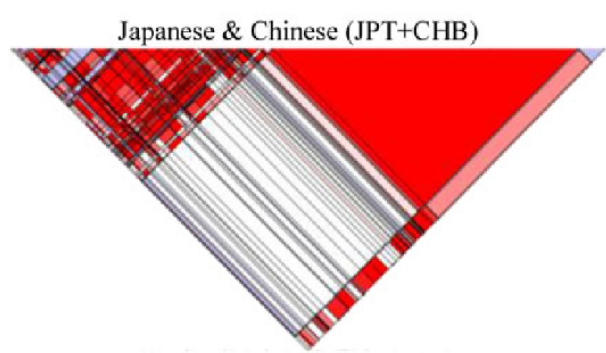

Western European (CEU)
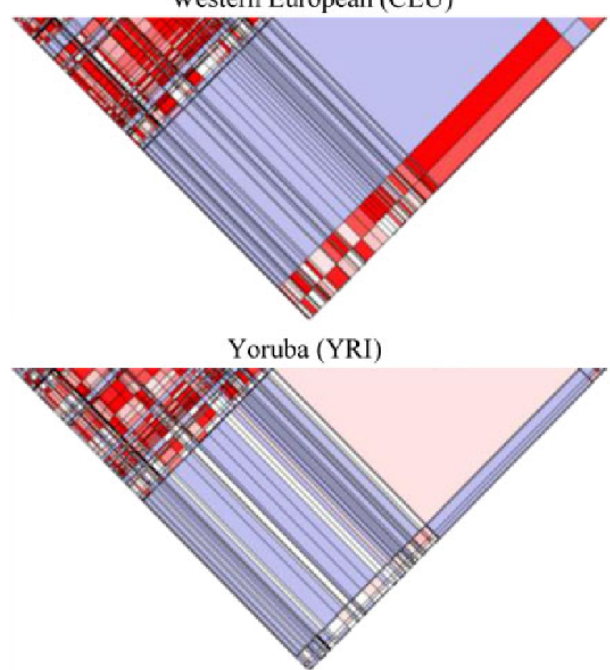

(b) LD structures across genomic region of chr9:72,469,776-72,551,350 including SNPs (rs7039780, rs4744608 and rs4744611)

Figure 5 Genomic features for LD structures in HapMap populations.

Table 4 Replication of GWAS of highLDLhighTG

\begin{tabular}{|c|c|c|c|c|c|c|c|c|c|c|c|c|c|c|}
\hline \multirow[t]{2}{*}{ SNP } & \multicolumn{3}{|c|}{ Ansung } & \multicolumn{3}{|c|}{ Ansan } & \multirow{2}{*}{$\begin{array}{c}\text { Combined } \\
\text { LDLTG } \\
n=545\end{array}$} & \multicolumn{3}{|c|}{ Male } & \multicolumn{3}{|c|}{ Female } & \multirow{2}{*}{$\begin{array}{c}\text { Combined } \\
\text { LDLTG } \\
n=545\end{array}$} \\
\hline & $\begin{array}{l}\text { LDLTG } \\
n=205\end{array}$ & $\begin{array}{l}\text { L-C } \\
=919\end{array}$ & $\begin{array}{l}\begin{array}{l}\mathrm{TG} \\
=936\end{array} \\
=9\end{array}$ & & $\begin{array}{c}\text { LDL-C } \\
n=1352\end{array}$ & $\begin{array}{c}\mathrm{TG} \\
\mathrm{n}=843\end{array}$ & & & & $\begin{array}{l}\text { TG } \\
=969\end{array}$ & & & $\begin{array}{c}\mathrm{TG} \\
\mathrm{n}=810\end{array}$ & \\
\hline 11700112 & $2.6 \times 10^{-2}$ & 0.1818 & 3849 & $3.1 \times 10^{-2}$ & 0.7172 & 0.0172 & $2.8 \times 10^{-2}$ & $1.8 \times 10^{-1}$ & 161 & 0.6321 & $1.0 \times 10^{-3}$ & 0.0967 & 0.0072 & $9.2 \times 10^{-2}$ \\
\hline rs6140956 & $8.8 \times 10^{-4}$ & 0.1770 & 0.1017 & & 0.7749 & 0.0332 & & & 0.6353 & 0.3125 & & 0.2317 & 0.0096 & \\
\hline rs6133716 & $1.8 \times 10^{-3}$ & 0.2691 & 0.0748 & $9.3 \times 10^{-2}$ & 0.7603 & 0.0701 & $4.7 \times 10^{-2}$ & $1.1 \times 10^{-1}$ & 0.9550 & 0.2231 & $1.9 \times 10^{-3}$ & 0.1757 & 0.0259 & $5.8 \times 10^{-2}$ \\
\hline rs9967942 & $2.6 \times 10^{-2}$ & 0.3476 & 0.4816 & $4.1 \times 10^{-2}$ & 0.6707 & 0.0198 & $3.3 \times 10^{-2}$ & $4.1 \times 10^{-1}$ & 0.2925 & 0.8325 & $6.9 \times 10^{-4}$ & 0.1545 & 0.0072 & $2.0 \times 10^{-1}$ \\
\hline rs11087847 & $1.9 \times 10^{-2}$ & 0.1531 & 0.3200 & $3.5 \times 10^{-2}$ & 0.7218 & 0.0151 & & & 0.4459 & 0.5424 & & 0.0750 & 0.0062 & \\
\hline rs2822994 & $1.1 \times 10^{-1}$ & 0.1582 & 0.2536 & & & 0.0019 & & & & 0.0060 & & & 32 & \\
\hline rs2822998 & $1.2 \times 10^{-1}$ & 0.1985 & 0.2456 & $7.4 \times 10^{-5}$ & 0.0172 & 0.0043 & $5.8 \times 10^{-2}$ & $3.2 \times 10^{-2}$ & 0.4875 & 0.0084 & $2.9 \times 10^{-4}$ & 0.0101 & 0.1361 & $10^{-2}$ \\
\hline rs1041404 & $1.6 \times 10^{-3}$ & 0.0668 & 0.0357 & $3.1 \times 10^{-3}$ & 0.0274 & 0.0338 & $2.4 \times 10^{-3}$ & $7.8 \times 10^{-3}$ & 0.3843 & 0.0049 & $4.4 \times 10^{-4}$ & 0.0094 & 0.0939 & $4.1 \times 10^{-3}$ \\
\hline rs9959874 & $1.2 \times 10^{-1}$ & 0.4953 & 0.1942 & $1.1 \times 10^{-3}$ & 0.0540 & 0.2536 & $5.9 \times 10^{-2}$ & $4.3 \times 10^{-3}$ & 0.4620 & 0.0720 & $1.8 \times 10^{-1}$ & 0.2007 & 0.9606 & $9.3 \times 10^{-2}$ \\
\hline 93506 & $1.2 \times 10^{-1}$ & 0.4953 & 0.1942 & & 84 & 0.2616 & & & 0.4620 & 0.0771 & & 0.2018 & 0.9797 & $.4 \times 10^{-2}$ \\
\hline rs4744611 & $1.7 \times 10^{-2}$ & 0.9652 & 0.0078 & $4.3 \times 10^{-2}$ & 0.0090 & 0.8933 & $3.0 \times 10^{-2}$ & $1.1 \times 10^{-3}$ & 0.0113 & 0.1925 & $1.8 \times 10^{-1}$ & 0.6221 & 0.4880 & $9.1 \times 10^{-2}$ \\
\hline rs7039780 & $7.8 \times 10^{-3}$ & 0.6334 & 0.0107 & $1.4 \times 10^{-1}$ & 0.0238 & 0.7387 & $78 \int^{2}$ & $2.2 \times 10^{-3}$ & 0.0080 & 0.2893 & $2.2 \times 10^{-1}$ & 0.6317 & 0.4947 & $1.1 \times 10^{-1}$ \\
\hline rs4744608 & $7.8 \times 10^{-3}$ & 0.5846 & 0.0122 & $1.6 \times 10^{-1}$ & 0.0253 & 0.6955 & $8.2 \times 10^{-2}$ & $1.8 \times 10^{-3}$ & 0.0074 & 0.2650 & $2.6 \times 10^{-1}$ & 0.6317 & 0.5936 & $1.3 \times 10^{-1}$ \\
\hline rs665770 & $2.3 \times 10^{-2}$ & 0.2715 & 0.3219 & $4.7 \times 10^{-2}$ & 0.0747 & 0.3156 & & $1.6 \times 10^{-2}$ & 0.5529 & 0.1529 & $8.1 \times 10^{-2}$ & 0.0321 & 0.6182 & $4.9 \times 10^{-2}$ \\
\hline rs529581 & $2.2 \times 10^{-2}$ & 0.2498 & 0.3413 & $4.5 \times 10^{-2}$ & 0.0524 & 0.3337 & $3.4 \times 10^{-2}$ & $2.4 \times 10^{-2}$ & 0.5012 & 0.1932 & $6.2 \times 10^{-2}$ & 0.0260 & 0.5976 & $4.3 \times 10^{-2}$ \\
\hline rs693 & $8.0 \times 10^{-3}$ & 0.0889 & 0.2148 & $1.1 \times 10^{-2}$ & .0045 & 0.0396 & $9.6 \times 10^{-3}$ & $2.1 \times 10^{-3}$ & 3 & 0.0147 & $2.8 \times 10^{-2}$ & 6 & 46 & $1.5 \times 10^{-2}$ \\
\hline
\end{tabular}

$\mathrm{n}$ represents number of cases. 


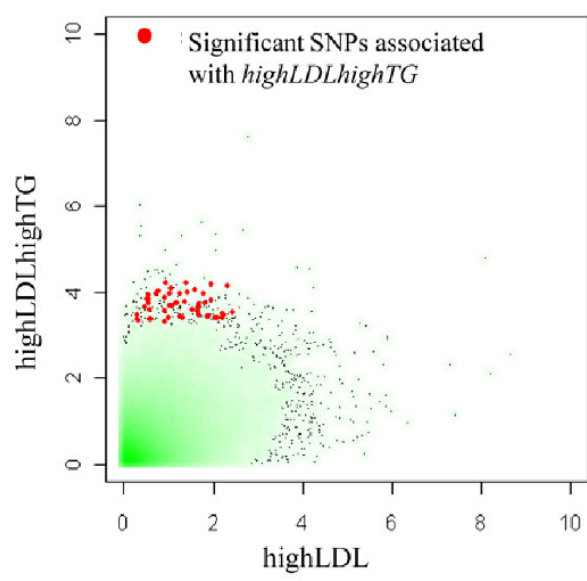

(a) highLDLhighTG vs. single trait high LDL

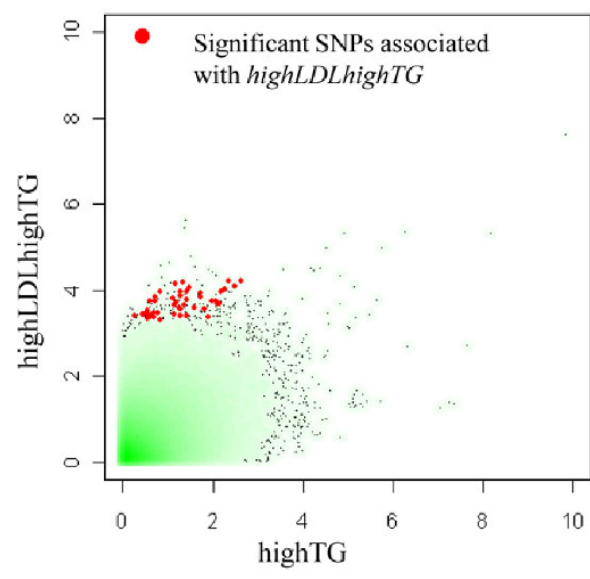

(b) highLDLhighTG vs. single trait high TG

Figure 6 Scatter plots for $p$-value for a multivariate trait versus single traits.

including $\mathrm{AD}$ and $\mathrm{PD}$ influenced by pleiotropic genetic factors. Thus, the genetic markers identified in our work can have pleiotropic effect on MS, BMD and neurodegenerative disorders.

\section{Gene network analysis using protein-protein interactions} We explored possible functional relationships between five of six genes associated with highLDLhighTG using STRING, a database of predicted protein-protein interactions (PPI). We obtained 5 different networks of genes interacting with each of five genes by confidence of association evidence $(\geq 0.5)$. Each of the gene networks (Figure 7) was mapped to KEGG pathways and examined pathways in common. Four genes i.e. BCL2, $N A V 1$, NIRP1 and TRPM3 interact with genes (CASP7, BACE1, $S D H B, T R P C 6)$ in $\mathrm{AD}$ and $\mathrm{PD}$ pathways, while $B C L 2$ and NIRP1 shared Huntington's disease as well as AD. In particular, three genes i.e. BCL2, PAK7, and NIRP1 shared pathways in cancer and other pathways, supporting our hypothesis that multivariate phenotypes have

Table 5 Phenotypes associated with QTLs mapped to 6 genes identified

\begin{tabular}{|c|c|c|c|}
\hline $\begin{array}{c}\text { Gene(s) } \\
\text { (chromosome } \\
\text { band) }\end{array}$ & OMIM phenotype (OMIM number) & Phenotypes for rat QTL from RGD & Phenotypes for mouse QTL from MGl \\
\hline $\begin{array}{c}\text { PAK7, } \\
\text { C20orf103 } \\
(20 \mathrm{p} 12.2)\end{array}$ & $\begin{array}{c}\text { Body mass index(608559), } \\
\text { Atopic dermatitis(605804), } \\
\text { Systemic lupus erythematosus(610065), } \\
\text { Glaucoma(608696), } \\
\text { Alzheimer disease(607116) }\end{array}$ & $\begin{array}{c}\text { Blood pressure, Body weight, } \\
\text { Cardiac mass, Stress response, } \\
\text { Non-insulin dependent diabetes mellitu, Renal } \\
\text { disease susceptibility, Thymus enlargement } \\
\text { suppressive }\end{array}$ & $\begin{array}{c}\text { Blood glucose level, } \\
\text { Type } 2 \text { diabetes mellitus, } \\
\text { Bone mineral density, Crescentic } \\
\text { glomerulonephritis, Modifier of retinal } \\
\text { degeneration }\end{array}$ \\
\hline $\begin{array}{c}\text { NRIP1 } \\
(21 q 11.2) \\
\end{array}$ & $\begin{array}{l}\text { Myeloproliferative syndrome(159595) } \\
\text { Narcolepsy(609039), Autism(610838) }\end{array}$ & Testicular tumor resistance & \\
\hline $\begin{array}{c}\mathrm{BCL2} \\
(18 \mathrm{q} 21.33)\end{array}$ & $\begin{array}{l}\text { Orthostatic hypotensive disorder } \\
\text { (143850), Insulin-dependent diabetes } \\
\text { mellitus(601941), Amyotrophic lateral } \\
\text { sclerosis(606640) }\end{array}$ & $\begin{array}{l}\text { Blood pressure, Cardiac cell morphology, } \\
\text { Insulin dependent diabetes mellitus, Renal } \\
\text { function }\end{array}$ & Bone mineral density \\
\hline $\begin{array}{c}\text { TRPM3 } \\
(9 q 21.11 \\
-9 q 21.13)\end{array}$ & $\begin{array}{l}\text { Hematocrit/hemoglobin quantitative trait } \\
\text { (609320), Cataract(605749), } \\
\text { Pelvic organ prolapse(613088), } \\
\text { Deafness (chromosome 9q21.11 } \\
\text { duplication syndrome)(613558), } \\
\text { Epilepsy(611631), paraplegia(607152), } \\
\text { Otosclerosis(612096), Spastic } \\
\text { Amyotrophic lateral sclerosis(105550) }\end{array}$ & $\begin{array}{c}\text { Blood pressure, Body weight, } \\
\text { Heart rate, Stress response, Cardiac mass, } \\
\text { Glucose level, Lipid level, } \\
\text { Renal function, Kidney mass, Renin } \\
\text { concentration, } \\
\text { Thyroid stimulating hormone level, } \\
\text { Abnormal inflammatory response, } \\
\text { Hepatocarcinoma susceptibility, }\end{array}$ & $\begin{array}{l}\text { Atherosclerosis, } \\
\text { Bone mechanical trait, } \\
\text { Autoimmune aoritis, } \\
\text { Cataract severity }\end{array}$ \\
\hline $\begin{array}{l}\text { NAV1 } \\
(1 \mathrm{q} 32.1)\end{array}$ & $\begin{array}{l}\text { Inflammatory bowel disease(612381), } \\
\text { Pseudohypoaldosteronism(145260), } \\
\text { Parkinson disease(613164), } \\
\text { Glomerulopathy(601894) }\end{array}$ & $\begin{array}{c}\text { Blood pressure, Cardiac mass, } \\
\text { Stress response, Renal function, } \\
\text { Thymus enlargement, } \\
\text { Abnormal inflammatory response }\end{array}$ & $\begin{array}{l}\text { Crescentic glomerulonephritis, } \\
\text { Bone mineral density }\end{array}$ \\
\hline
\end{tabular}

Phenotypes associated with QTLs were extracted from Phenotype and Disease Association tracks in UCSC genome browser. Phenotypes for OMIM, rat QTL, mouse QTL corresponded to OMIM phenotype loci, RGD RAT QTL and MGI Mouse QTL tracks respectively. 


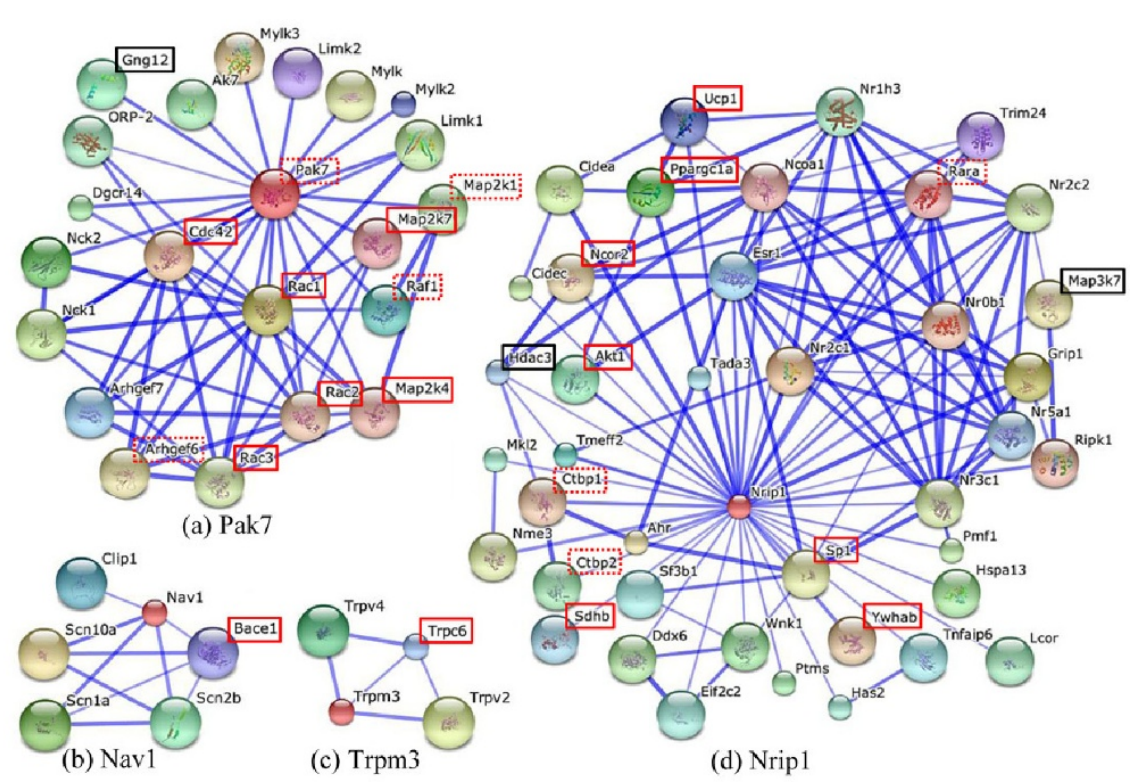

Figure 7 Gene networks constructed from interacting proteins. Solid lines in red stand for genes in pathways for $A D, P D, H D$, and ALS. Gene symbols in black are involved in chemokine, MAPK and Wnt signaling pathways. Dashed lines in red represent genes mapping to pathways in cancer from KEGG DB or specific cancer related pathways annotated by PANTHER and DAVID functional annotations.

common etiology pathways when they are affected by pleiotropic genetic factors.

\section{Conclusions}

We have showed a methodology to identify genetic markers associated with multivariate phenotypes derived from patterns of phenotypic associations discovered by ARM. An application of a large scale mining approach to anthropometric and biochemical traits has not been previously reported.

The patterns of phenotypic associations were visualized with connected graphs which were informative to draw relations between plasma lipid levels with BMD and a cluster of common traits (Obesity, hypertension, insulin resistance) related to MS. These putative patterns of the phenotypic associations were in concordance with the fact that MS increases T2D and CVD [20]. More interesting finding was observed in that BMD was associated with high levels of glucose but not with insulin levels although the association between high glucose levels or insulin resistance with BMD has been inconclusive. We suggest that multiple phenotypic associations between plasma lipid levels with BMD and common traits in MS, be affected by the common genes harbouring pleiotropic effects.

For the identification of pleiotropic genes, we derived multivariate phenotype highLDLhighTG from the association patterns of two single traits high LDL and high TG, which subdivided samples into feasible sizes of cases and controls for GWAS. Multivariate phenotype
highLDLhighTG increased the strength of phenotypic associations with the correlated single traits by additive effect of multiple single traits. Out of 17 traits linked to single traits high LDL and high TG, four traits (DS, GLU0, INS0, and SONA) have more power in distinctively classifying samples of highLDLhighTG into cases and controls when the single traits were combined into the multivariate phenotype.

Our approach to GWAS of multivariate highLDLhighTG identified 15 SNPs in six genes (PAK7, C20orf103, NRIP1, BCL2, TRPM3, and NAV1). While pvalues $\left(9.6 \times 10^{-5} \leq \mathrm{P} \leq 1.2 \times 10^{-4}\right)$ of genetic variants in the six genes were less significant than those identified in general GWAS due to limited sizes of the sample those genes were not detectable within univariate framework of the GWAS. Effect sizes (odds raios=1.34-1.60) of the variants ranged between modest and intermediate sizes were comparable to those in the general GWAS. Relevance of the six genes to CVD in MS was apparently explained in previous work.

According to analysis based on rat and mouse QTL $\mathrm{DB}$, our results suggest that the six genes were mapped to QTLs associated with common traits related to MS, supporting that highLDLhighTG represents one of pleiotropic patterns related to MS and the six genes associated with it can influence the pleiotropic effects on MS. In particular, we showed possibility that hyperlipidemia may be linked to pathogenic associations with osteoporosis and neurodegenerative disorders including $\mathrm{AD}$ and PD by incorporating associations of OMIM 
phenotypes with PPI networks for the six genes. We have found that four genes i.e. BCL2, NAV1, NIRP1 and TRPM3 may share AD and PD pathways where interacting genes with them are involved. Three genes i.e. BCL2, $P A K 7$, and NIRP1 also share common pathways in cancer.

Clinical association studies for 4 genes i.e. PAK7, C20orf103, TRPM3 and NAV1 have not yet been found although characteristics of genomic features for the four genes are also suggestive to investigate further study. Our work emphasize that multivariate phenotypes based GWAS can identify pleiotropic genes that share common etiology pathways.

\section{Additional material}

\section{Additional file 1: Description of traits. A table shows 52 traits and}

their description and measurement.

Additional file 2: Basic characteristics for traits. Baseline

characteristics according to means and standard deviations.

Additional file 3: Association rules encoding high TG and high LDL

levels. Representative association rules encoding high TG and high LDL.

Additional file 4: Features for genomic regions and LD structures.

\section{Acknowledgements}

The KARE genotype and epidemiological data were gratefully made available by National Institute of Health, Korea Centre for Disease Control, through the KARE Analysis Consortium. This work was supported by Basic Science Research Program through the National Research Foundation of Korea (NRF) funded by the Ministry of Education, Science and Technology (NRF-2010-0021811).

This article has been published as part of BMC Systems Biology Volume 5 Supplement 2, 2011: 22nd International Conference on Genome Informatics: Systems Biology. The full contents of the supplement are available online at http://www.biomedcentral.com/1752-0509/5?issue=S2.

\section{Authors' contributions}

SHP developed the concept and the method. JYL implemented a module for visualizations of association rules with networks and participated in drafting the paper. SK interpreted the results for the point of view of biology. SHP drafted the paper and JYL and SK were contributed to finalize the draft.

\section{Competing interests}

The authors declare that they have no competing interests.

Published: 14 December 2011

\section{References}

1. Manolio TA, Collins FS, et al: Finding the missing heritability of complex diseases. Nature 2009, 461:747-753.

2. Yang $\mathrm{Q}$, Wu H, Guo CY, Fox CS: Analyze multivariate phenotypes in genetic association studies by combining univariate association tests. Genet Epidemiol 2010, 34:444-454

3. Weedon MN, Frayling TM: Reaching new heights: insights into the genetics of human stature. Trends Genet 2008, 24:595-603.

4. Winckler W, Weedon MN, et al: Evaluation of common variants in the six known maturity-onset diabetes of the young (MODY) genes for association with type 2 diabetes. Diabetes 2007, 56:685-693.
5. Gudmundsson J, Sulem P, et al: Two variants on chromosome 17 confer prostate cancer risk, and the one in TCF2 protects against type 2 diabetes. Nat Genet 2007, 39:977-983.

6. Miyamoto $Y$, Mabuchi A, et al: A functional polymorphism in the $5^{\prime}$ UTR of GDF5 is associated with susceptibility to osteoarthritis. Nat Genet 2007, 39:529-533.

7. Southam L, Rodriguez-Lopez J, et al: An SNP in the 5'-UTR of GDF5 is associated with osteoarthritis susceptibility in Europeans and with in vivo differences in allelic expression in articular cartilage. Hum Mol Genet 2007, 16:2226-2232.

8. Gibson G: Hints of hidden heritability in GWAS. Nat Genet 2010, 42:558-560.

9. Fitzmaurice GM, Laird NM: Likelihood-based method for analysing longitudinal binary responses. Biometrika 1993, 80:141-151.

10. Laird NM, Ware JH: Random-effects models for longitudinal data. Biometrics 1982, 38:963-974.

11. Liu J, Pei Y, Papasian CJ, Deng HW: Bivariate association analyses for the mixture of continuous and binary traits with the use of extended generalized estimating equations. Genet Epidemiol 2009, 33:217-227.

12. O'Brien PC: Procedures for comparing samples with multiple endpoints. Biometrics 1984, 40:1079-1087.

13. Xu X, Tian L, Wei L: Combining dependent tests for linkage or association across multiple phenotypic traits. Biostatistics 2003, 4:223-229

14. Park SH, Kim S: Discovery of multivariate phenotypes using association rule mining and their application to genome -wide association studies. Bioinformatics and Biomedicine Workshops (BIBMW); Honkong, China IEEE International Conference; 2010, 324-329.

15. Cho YS, Go MJ, Kim YJ, et al: A large-scale genome-wide association study of Asian populations uncovers genetic factors influencing eight quantitative traits. Nat Genet 2009, 41:527-534.

16. Agrawal R, Srikant R: Fast algorithms for mining association rules in large databases. VLDB 1994, 487-499.

17. Park S, Reyes J, Gilbert D, Kim J, Kim S: Prediction of protein-protein interaction types using association rule based classification. $B M C$ Bioinformatics 2009, 10:36.

18. Brin S, et al: Dynamic itemset counting and implication rules for market basket data. SIGMOD '97 ACM; 1997.

19. Purcell $S$, Neale B, et al: PLINK: a tool set for whole-genome association and population-based linkage analyses. Am J Hum Genet 2007, 81:559-575.

20. Mitrakou A: Women's health and the metabolic syndrome. Ann N Y Acad Sci 2006, 1092:33-48.

21. von Muhlen D, Safii S, Jassal SK, Svartberg J, Barrett-Connor E: Associations between the metabolic syndrome and bone health in older men and women: the Rancho Bernardo Study. Osteoporos Int 2007, 18:1337-1344.

22. Yamaguchi T, Sugimoto T, Yano S, et al: Plasma lipids and osteoporosis in postmenopausal women. Endocr J 2002, 49:211-217.

23. Inaba M: Secondary osteoporosis: thyrotoxicosis, rheumatoid arthritis, and diabetes mellitus. J Bone Miner Metab 2004, 22:287-292.

24. Lehrman MA, Goldstein JL, et al: Internalization-defective LDL receptors produced by genes with nonsense and frameshift mutations that truncate the cytoplasmic domain. Cell 1985, 41:735-743.

25. WTCCC: Genome-wide association study of 14,000 cases of seven common diseases and 3,000 shared controls. Nature 2007, 447:661-678.

26. Naylor J, Li J, Milligan CJ, et al: Pregnenolone sulphate- and cholesterolregulated TRPM3 channels coupled to vascular smooth muscle secretion and contraction. Circ Res 2010, 106:1507-1515.

27. Ren $Y$, Sun $C$, et al: PPAR gamma protects cardiomyocytes against oxidative stress and apoptosis via Bcl-2 upregulation. Vascul Pharmacol 2009, 51:169-174.

28. Lu Y, Dolle ME, et al: Multiple genetic variants along candidate pathways influence plasma high-density lipoprotein cholesterol concentrations. J Lipid Res 2008, 49:2582-2589.

29. Herzog B, Hallberg $M$, et al: The nuclear receptor cofactor, receptorinteracting protein 140 , is required for the regulation of hepatic lipid and glucose metabolism by liver $\mathrm{X}$ receptor. Mol Endocrinol 2007, 21:2687-2697.

30. Silander $K$, Alanne $M$, et al: Gender differences in genetic risk profiles for cardiovascular disease. PLoS One 2008, 3:e3615. 
31. Sutedja NA, van der Schouw YT, et al: Beneficial vascular risk profile is associated with amyotrophic lateral sclerosis. J Neurol Neurosurg Psychiatry 2011, 82:638-642.

32. Frisardi $V$, Solfrizzi $V$, et al: Metabolic-cognitive syndrome: a cross-talk between metabolic syndrome and Alzheimer's disease. Ageing Res Rev 2010, 9:399-417.

doi:10.1186/1752-0509-5-S2-S13

Cite this article as: Park et al: A methodology for multivariate

phenotype-based genome-wide association studies to mine pleiotropic genes. BMC Systems Biology 2011 5(Suppl 2):S13.

Submit your next manuscript to BioMed Central and take full advantage of:

- Convenient online submission

- Thorough peer review

- No space constraints or color figure charges

- Immediate publication on acceptance

- Inclusion in PubMed, CAS, Scopus and Google Scholar

- Research which is freely available for redistribution

Submit your manuscript at www.biomedcentral.com/submit
C Biomed Central 